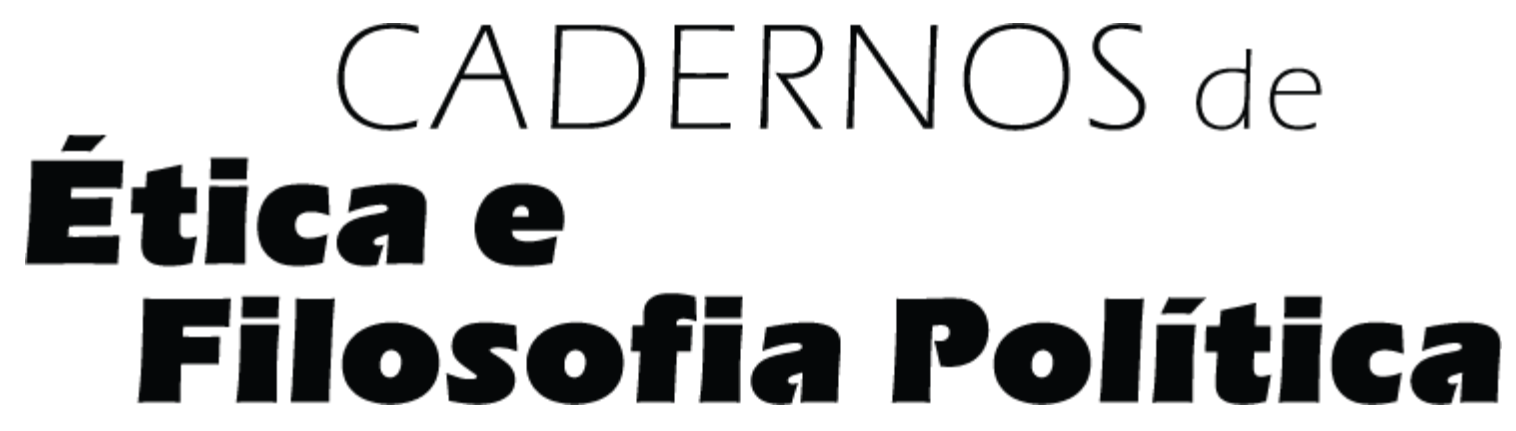

NÚMERO 35

DOSSIÊ ESPECIAL

FOUCAULT, POLÍTICAS DA ARQUEOLOGIA 50 ANOS DE A ARQUEOLOGIA DO SABER (1969)

FFLCH

Ю 


\section{CADERNOS de Ética e Filosofia Politica}

\section{CADERNOS DE ÉTICA E FILOSOFIA POLÍTICA}

\author{
No 35 - São Paulo - $2^{\circ}$ semestre de 2019 \\ Publicação semestral - ISSN 1517-0128
}

Editores: Maria das Graças de Souza (responsável institucional), Alessandra Tsuji, André Manoel do Nascimento, Caio Eduardo Cunha Leitão, Christiane Cardoso Ferreira, Eugênio Mattioli Gonçalves, Giovani Valério Graciano Borges, Lourenço Fernandes Neto Silva, João Pedro Argondizo Correia, Priscila Aragão Zaninetti, Taynam Santos Luz Bueno, Thiago Dias da Silva, Thiago Vargas Escobar Azevedo, Victor Fiori.

Conselho Editorial: Conselho Editorial: Alberto Ribeiro de Barros (USP), Antônio Carlos dos Santos (UFS), Cláudio Boeira Garcia (Unijuî), Jaimir Conte (UFRN), José Oscar de Almeida Marques (Unicamp), Jose Thomaz Almeida Brum Duarte (PUC-RJ), Helena Esser dos Reis (UFG), Luiz Felipe Netto de Andrade e Silva Sahd (UFU), Luiz Fernando Batista Franklin de Mattos (USP), Maria Lúcia Mello e Oliveira Cacciola (USP), Marilena de Souza Chaui (USP), Milton Meira do Nascimento (USP), Miroslav Milovic (UnB), Newton Bignotto (UFMG), Patrícia Fontoura Aranovich (Unifesp), Paulo Jonas de Lima Piva (USJT), Renato Janine Ribeiro (USP), Ricardo Monteagudo (Unesp), Rodrigo Brandão (UFPR), Rolf Kuntz (USP), Ruy Fausto (USP), Sérgio Cardoso (USP).

Imagem de capa: Diego Velázquez, Las Meninas (1656)

\author{
USP \\ Universidade de São Paulo \\ Reitor: Prof. Dr. Vahan Agopyan \\ Vice-reitor: Prof. Dr. Antonio Carlos Hernandes
}

FFLCH

Faculdade de Filosofia, Letras e Ciências Humanas

Diretora: Prof. Dr. Maria Arminda do Nascimento

Arruda

Vice-Diretor: Paulo Martins

Departamento de Filosofia da USP

Chefe: Prof. Oliver Tolle

Vice-chefe: Prof. Luiz Sérgio Repa

Coordenador do Programa de Pós-Graduação:

Prof. Carlos Eduardo de Oliveira

Prof. Maurício Cardoso Keinert

Endereço para correspondência e aquisição:

Profa. Maria das Graças de Souza

Departamento de Filosofia - USP

Av. Prof. Luciano Gualberto, 315

05508-900 - São Paulo - SP - Brasil

Tel.: (0xx11) 3091-3761 - Fax: (0xx11) 3031-2431

E-mail: cefp@usp.br

Cadernos de Ética e Filosofia Política é uma publicação do Programa de Pós-Graduação do Departamento de Filosofia da Universidade de São Paulo.

Os artigos deste periódico são indexados por: The Philosopher's Index e Latin Americanist Research Resources Project - LARRP

WWW.REVISTAS.USP.BR/CEFP 


\section{APRESENTAÇÃO}

Os Cadernos de Ética e Filosofia Política surgiram da necessidade que nós, pesquisadores do Departamento de Filosofia da Universidade de São Paulo, tínhamos da publicação de trabalhos recentes, pondo em debate as pesquisas ligadas a um ramo do saber que cada vez mais assume importância dentro e fora do meio acadêmico. Estes Cadernos visam suprir em alguma medida esta demanda, fornecendo bibliografia a um público interessado no caráter multifacetado da reflexão sobre a ética e a política.

As questões relativas ao direito, à história, à religião e às artes não raro são por elas incorporadas, convertendo a um só tempo em sua matéria de investigação e seu cenário de intervenção. É este caráter abrangente da ética e da filosofia política que lhes concede a virtude da vivacidade. Os Cadernos sempre procuraram corresponder e promover essa virtude, veiculando sobretudo a produção teórica discente, sem distinguir correntes ideológicas, linhas filosóficas ou áreas de saber incluídos nas mais diversas manifestações de reflexão. Aqui se encontrarão artigos, ensaios, resumos de teses e dissertações, resenhas, traduções de trechos de obras e de pequenas obras.

A revista é editada em meio eletrônico, o que resulta em um ganho substancial de qualidade, pois facilita o acesso e a difusão dos textos. Somando-se a isso, contamos com um corpo de pareceristas especializados nos temas, correntes filosóficas e autores enfocados pelos artigos, o que torna mais democrática a escolha dos textos destinados à publicação. É importante notar que segundo as normas das agências de fomento, o valor de um artigo publicado por meio eletrônico equivale ao de um artigo impresso.

Convidamos todos os estudantes de filosofia e pesquisadores interessados em publicar seus trabalhos a colaborar conosco, ajudando-nos a diminuir assim a distância entre a pesquisa individual e o diálogo aberto com autores e críticos.

Os Editores 


\section{SUMÁRIO}

Três razões para obedecer, segundo Thomas Hobbes

Felipe Moralles e Moraes.

Variações estéticas e políticas sobre um pensamento não-representativo

André Vinícius Nascimento Araújo.

DOSSIÊ FOUCAULT, POLÍTICAS DA ARQUEOLOGIA: 50 anos de $\boldsymbol{A}$ arqueologia do saber

\section{APRESENTAÇÃO DO DOSSIÊ}

$\mathrm{Na}$ orla do tempo, os mil rostos de nossa atualidade: porque ainda a Arqueologia

Carlos Eduardo Ribeiro, Silvio Ricardo Gomes Carneiro e Victor Fiori Augusto.

Sobre o descentramento do sujeito: transgredindo os limites kantianos

Suze de Oliveira Piza e Izabela Loner Santana.

Formação, alcance e embaraços da arqueologia do saber: a política das relações nas condições históricas de possibilidade

Fillipa Carneiro Silveira......

Miserável ou irracional: os marxistas brasileiros recepcionam Foucault

Felipe Luir.

O panoptismo eletrônico virtual e sua ameaça ao exercício da atitude crítica

Cesar Candiotto e Silvio Couto Neto.

“Em pleno Foucault”: arqueologia e engajamento político

Daniela Lima.

De Canguilhem a Foucault, em torno da psicologia

Marcio Luir. Miotto.

Uma arqueologia da sociologia?

Marcos Lacerda. 
Byron e o byronismo no centro da epistémê moderna

Pedro Augusto Pinto e Pedro Ivan Moreira de Sampaio.

Da fundamentação antropológica da psicologia à crítica antropológica de história da loucura de Michel Foucault

Raphael Thomas Ferreira Mendes Pegden.

Política e análise do discurso na arqueologia de Foucault

Daniel Verginelli Galantin e Thiago Fortes Ribas.

A arqueologia e a política do anti-humanismo

Lara Pimentel Figueira Anastacio.

Há ainda alguma relevância à arqueologia? Considerações entre história dos

discursos de verdade e de poder

Marcos Nalli...

Arqueologia e magia

Tiago Brentam Perencini.

\section{RESENHA}

Foucault and the human subject of science, de Garðar Árnason

Jonas Muriel Backendorf.....

\section{TRADUÇÃO}

Um Foucault neoliberal?

Edgardo Castro (Tradução: Mario Antunes Marino).

Obrigação política e a sociedade aberta

Alessandro Passerin D'Entrèves (Tradução: Maísa Martorano Suarez Pardo). 